\title{
O EXAME FÍSICO DA TIREÓIDE
}

\author{
THYROID EXAM
}

Léa M. Z. Maciel

Docente. Divisão de Endocrinologia. Faculdade de Medicina de Ribeirão Preto - USP

Correspondência: Av. Bandeirantes, 3900 / 14048 - 900 - Ribeirão Preto - SP / FAX: (16) 6331144 / e-mail: Imzmacie@fmrp.usp.br

Maciel LMZ. O exame físico da tireóide. Medicina (Ribeirão Preto) 2007; 40 (1): 72-77.

RESUMO: O exame físico da tireóide é considerado difícil para uma grande maioria de médicos e deverá fazer parte da avaliação sistemática de um paciente pois, muitas vezes, só através dele é possível fazer diagnósticos de distúrbios tireoidianos. Ele compreende a inspeção, palpação e ausculta. A glândula normal, geralmente, não é visível. Para a realização da palpação é imprescindível a correta localização anatômica da glândula. O tamanho dos lobos, assim como sua consistência e mobilidade, a presença de dor ou alterações de sua superfície devem ser assinalados. Com dados da palpação, a tireóide será classificada como de tamanho normal ou aumentado (bócio) e se este bócio é difuso ou nodular. Caso um nódulo ou mais nódulos sejam palpados, o bócio é classificado em bócio uninodular e bócio multinodular, respectivamente. A ausculta da glândula é reservada a pacientes que apresentam sintomas e/ou sinais de hipertireoidismo.

Descritores: Glândula Tireóide. Exame Físico.

\section{1- INTRODUÇÃO}

O exame sistemático da glândula tireóide deve fazer parte do exame físico por duas razões principais:

1) A palpação é a única maneira para a detecção de certas doenças de tireóide e para o início da investigação etiológica.

2) A determinação do tamanho, consistência, presença de nodulações ou dor na glândula freqüentemente é necessária para uma adequada interpretação da história, de outros achados do exame físico geral, assim como dos resultados laboratoriais.

Alguns exemplos são ilustrativos de situações clínicas nas quais o exame da tireóide será de grande valor diagnóstico: a) Paciente com febre, "dor de garganta" ou dor nos ouvidos e ao exame do pescoço for encontrado dor na projeção da glândula tireóide, o quadro clínico será muito sugestivo de tireoidite subaguda (viral) ${ }^{1}$. Se a glândula não for palpada, ou este achado ignorado, uma conclusão inapropriada será obtida e alguns pacientes poderão ficar meses em tratamento com antibióticos, sem resolução do quadro.

b) Paciente com rouquidão e ao exame da glândula tireóide for encontrado um nódulo e caso seja demonstrado paralisia de corda vocal ipsilateral ao nódulo, o diagnóstico de carcinoma tireoidiano será o mais provável. Do mesmo modo, um carcinoma de tireóide será muito provável se, na palpação do pescoço, for encontrada adenomegalia cervical ipsilateral ao nódulo palpado ${ }^{2}$. 
c) Paciente com sintomas inespecíficos tais como: cansaço fácil, depressão, dores musculares ou articulares, mas, se ao exame físico, for encontrada tireóide aumentada de tamanho, com consistência firme e superfície irregular, o diagnóstico mais provável será hipotireoidismo primário decorrente de tireoidite auto-imune (Tireoidite de Hashimoto) ${ }^{3}$.

A glândula tireóide é formada por dois lobos ligados pelo istmo e encontra-se intimamente aderida à traquéia. Os lobos se justapõem à face lateral da traquéia e do esôfago desde a cartilagem tireóide até o sexto anel da traquéia. Os lobos são cobertos pelos músculos esterno-cleido-mastoideo, esterno-ióideo e esterno-tireóideo.

\section{2- INSPECÇÃO}

Normalmente a tireóide não é visível, exceto em pacientes muito emagrecidos ${ }^{4} \mathrm{O}$ paciente deverá estar sentado e a glândula é mais facilmente visualizada quando se estende a cabeça do paciente para trás e com a deglutição (Figura 1). Como a glândula é fixa à fáscia pré-traqueal, ela se desloca para cima com a deglutição do paciente. Assim, muitos bócios difusos ou nodulares são facilmente documentados durante a deglutição. Nos aumentos difusos da glândula, as duas faces laterais e a anterior do pescoço ficam uniformemente abauladas. É importante frisar que adiposidade cervical algumas vezes é confundida com bócio, devendo-se notar, porém, que ela não se desloca à deglutição.
Nos crescimentos nodulares da glândula (bócios nodulares) ocorrem abaulamentos locais, surgindo assimetrias no pescoço. Deve-se observar, também, desvios da traquéia, uma vez que o desvio lateral poderá sugerir lobo tireoidiano aumentado, bócio subesternal ou outra anormalidade torácica.

\section{3- PALPAÇÃO}

É mais fácil aprender a palpar a tireóide quando se examina a glândula pela frente, com o paciente sentado (Figura 2). O pescoço do paciente deverá ficar com a cabeça discretamente fletida para frente, uma vez que a palpação é mais difícil quando os músculos esterno-cleido-mastoideos ficam estendidos. A glândula tireóide é palpável na maioria dos indivíduos normais, apresentando lobos com cerca de 3 a $5 \mathrm{~cm}$ no sentido vertical e o istmo com diâmetro aproximado de $0,5 \mathrm{~cm}$.

\section{$O 1^{\circ}$ passo na palpação é localizar a glândula}

Para localizá-la deveremos verificar a posição das cartilagens tireóidea e cricóide, uma vez que o istmo da glândula tireóide se situa imediatamente abaixo da cartilagem cricóide. Em muitos pacientes idosos, particularmente naqueles que apresentam cifose torácica ou enfisema pulmonar, a cartilagem cricóide e a glândula tireóide ficam abaixo da fossa supra esternal, de modo que a glândula posiciona-se sob o esterno e dificilmente será palpada.

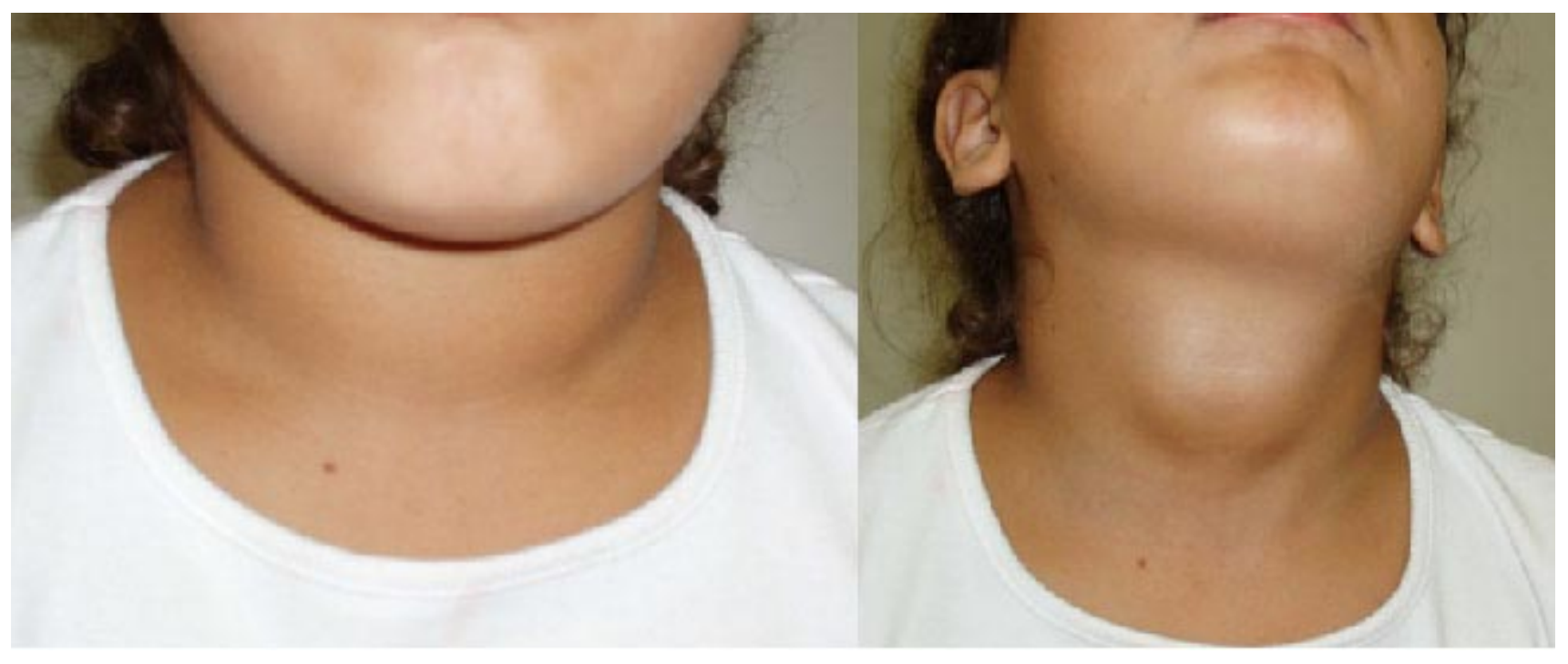

Figura 1: Inspeção da Tireóide. A) Paciente com a cabeça na posição normal. B) O mesmo paciente com a cabeça estendida para trás. 


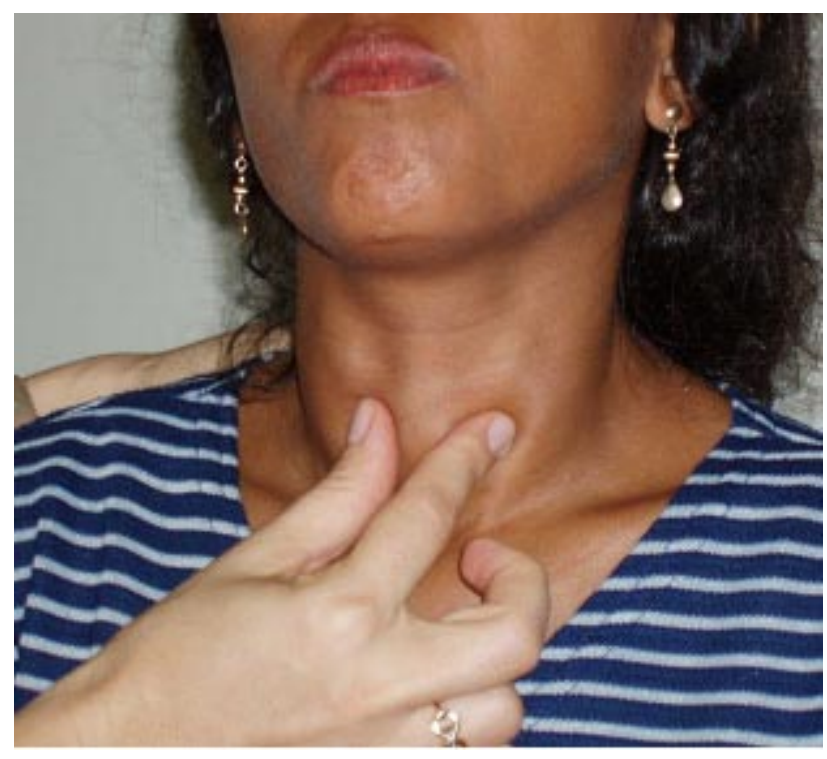

Figura 2. Localização da glândula tireóide

O istmo da glândula poderá ser examinado colocando-se o polegar direito, horizontalmente, abaixo da cartilagem cricóide. A palpação deverá permitir a percepção do istmo quando o paciente deglutir, ele apresenta consistência borrachosa e mede cerca de $0,5 \mathrm{~cm}$ de largura. $\mathrm{O}$ istmo com tamanho aumentado, firme ou com nódulos é uma indicação de anormalidade tireoidiana.

Com o polegar poderá também ser palpado o lobo piramidal, caso esteja presente. Esta estrutura, grosseiramente triangular, tem a orientação vertical e mais frequientemente se situa na borda medial do lobo E. Ele é mais facilmente palpado quando se desloca o polegar para trás e para frente no plano horizontal acima do ístmo. Quando o lobo piramidal é facilmente palpado, isto geralmente indica anormalidade tireoidiana (tireoidite de Hashimoto ou Doença de Graves), embora ele possa ser encontrado em tireóides normais.

\section{PALPAÇÃO DOS LOBOS}

\section{Método 1}

$\mathrm{O}$ examinador deve se posicionar à direita, à frente do paciente. Após a localização do istmo da tireóide, posicionar os dedos polegar e indicador direitos em cada um dos lado da traquéia (Figura 2), e solicitar ao paciente que degluta; desta maneira, o examinador poderá sentir a glândula, bilateralmente, passando pelos dedos.
Os lobos, deverão ser palpados também individualmente. Colocar os dedos indicador e médio da mão $\mathrm{D}$ justapostos quando for palpar o lobo esquerdo da glândula. O lobo D, do mesmo modo, é palpado com a mão E, estando o médico posicionado à esquerda do paciente. A deglutição (a seco ou com água) é útil para permitir a percepção do deslocamento da glândula sob os dedos. Desta forma a parte caudal dos lobos ou os contornos dos nódulos serão melhor percebidos. O tamanho, as características da superfície, a consistência e a presença de dor durante o exame de cada lobo deverão ser avaliados.

\section{Método 2}

Colocando-se à direita um pouco à frente do paciente, o dedo polegar E do examinador é deslizado para palpar o lobo E da tireóide. Na palpação do lobo D, o polegar D poderá ser utilizado (Figura 3 ).

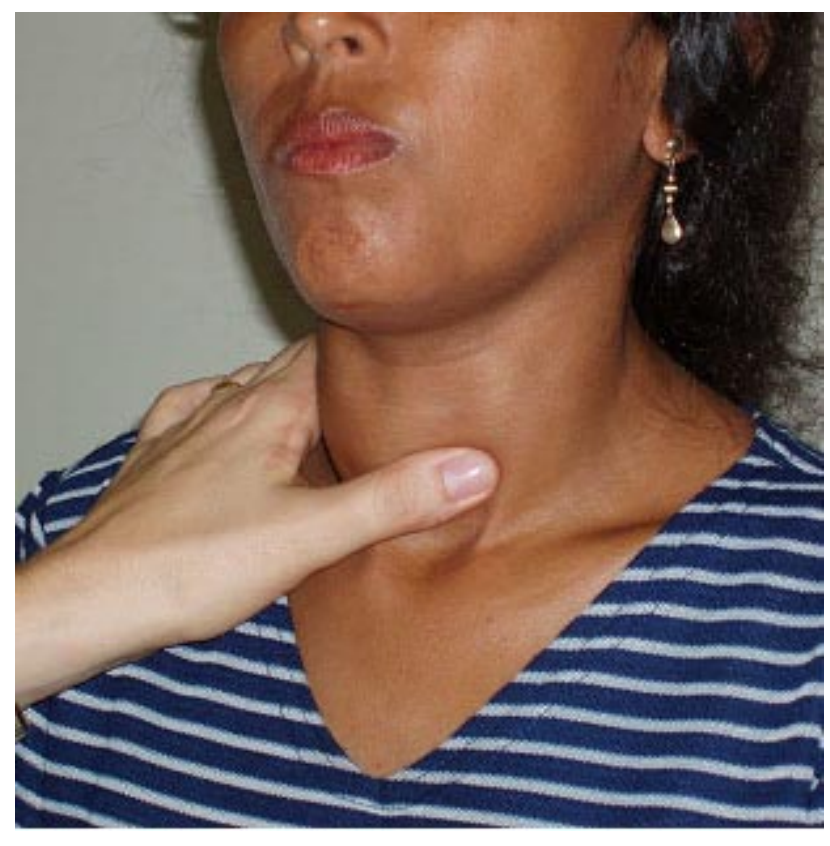

Figura 3. Palpação da tireóide com o polegar.

\section{Método 3}

O paciente deverá estar sentado e o examinador em pé atrás do paciente. $O$ paciente deverá fletir a cabeça para o lado a ser examinado para descontrair o músculo e os dedos indicador e médio do observador penetram na face interna daquele músculo e exploram o lobo da glândula (Figura 4), deslizando com os dedos desde a cartilagem tireóidea até o $6^{\circ}$ anel da traquéia. A manobra é repetida para o outro lobo. A 
deglutição deverá ser solicitada pois a identificação da glândula é facilitada com este procedimento.

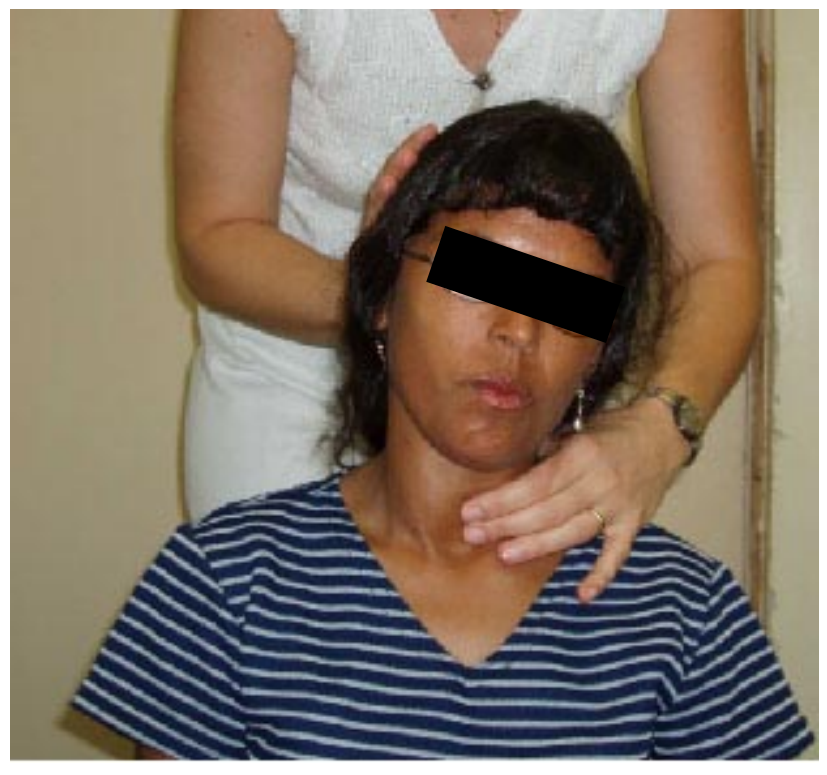

Figura 4. Palpação da tireóide por trás do paciente, com a cabeça em flexão homônima ao lado a ser palpado

\section{Ausculta}

A Ausculta da glândula tireóide deverá ser realizada em todos os pacientes com tireotoxicose, pois o aumento do fluxo sangüíneo poderá determinar a ocorrência de sopros sobre a glândula, algumas vezes acompanhados de frêmitos.

\section{NÓDULOS TIREOIDIANOS}

A palpação de nódulos depende de sua localização, tamanho e da anatomia do pescoço. Em pacientes jovens e magros, nódulos superficiais de pequenas dimensões, cerca de 0,5 a $1,0 \mathrm{~cm}$, poderão ser palpados. Em pacientes idosos ou com pescoços musculosos, apenas nódulos maiores são evidenciados à palpação.

É essencial medir as dimensões dos nódulos nos eixos vertical e horizontal. O método mais comumente empregado utiliza uma fita crepe: as bordas inferiores, superiores e látero-laterais são assinaladas no pescoço do paciente; uma fita crepe é colocada no pescoço sobre o local a ser medido, os limites são assinalados na fita que, posteriormente, é colada no prontuário do paciente. É aconselhável fazer um desenho para se registrar o que foi medido. Este método apresenta boa acurácia e permite observação seriada do paciente.
Deve-se, sempre, suspeitar da existência de um nódulo quando, à palpação, for percebido um "lobo" de um lado e não for sentido o lobo do lado oposto. Esta situação só não representará um nódulo caso o paciente apresente hemiagenesia tireoidiana, decorrente de hipertrofia compensatória do lobo contralateral ${ }^{5}$.

A maioria dos nódulos tireoidianos são benignos, ${ }^{2}$ movem-se livremente, têm superfície lisa e são de consistência borrachosa. Nódulos benignos podem ser rígidos, principalmente se calcificados ou tensos e distendidos por fluído. Um nódulo doloroso provavelmente indica degeneração hemorrágica ou infarto no interior de um nódulo benigno, ou ainda, tireoidites virais. Deve-se mencionar, porém, que alguns nódulos malignos também são dolorosos. Nódulos que não se mobilizam à deglutição requerem especial atenção, pois podem não corresponder à glândula tireoidiana (Ex. adenomegalia). Alternativamente, poderá representar carcinoma tireoidiano fixo a estruturas do pescoço pela infiltração muscular ou nódulos que fazem parte de um bócio mergulhante.

Cistos do tireoglosso usualmente surgem na linha mediana, desde a base da língua até o istmo da tireóide, poucos deles são lateralizados. Eles se elevam com a deglutição, como os nódulos, mas sua ligação com a base da língua também faz com que se elevem quando a língua é colocada para fora.

Nódulos malignos podem ser firmes ou duros e irregulares, mas a maioria são indistintos de nódulos benignos. É importante frisar, novamente, que, quando se encontra adenomegalia cervical ipsilateral ao nódulo tireoidiano palpado, existe alta probabilidade de este nódulo ser maligno, o que também se configura quando da presença de nódulo tireoidiano e rouquidão secundária a paralisia da corda vocal ipsilateral ao mesmo.

\section{BÓCIOS}

O termo bócio aplica-se para quando identifica-se um aumento da glândula tireóide de qualquer etiologia. Os bócios podem ser simétricos, assimétricos ou nodulares (uni ou multinodulares) ${ }^{6}$. Uma boa estimativa do tamanho poderá ser obtida medindo-se diretamente o tamanho dos lobos utilizando-se uma fita crepe, assinalando previamente o polo superior e o inferior do mesmo, como foi mencionado na medição dos nódulos. Em pacientes com grandes bócios, a medida de circunferência do pescoço, no ponto mais 
proeminente, facilita a avaliação do crescimento destes bócios.

Alguns examinadores descrevem bócios com aumentos de 1x, 2x ou 3x, etc para indicar se o bócio é de 1,2 ou 3 , ou mais vezes aumentado em relação do tamanho normal. Outros assinalam o peso máximo de $20 \mathrm{~g}, 40 \mathrm{~g}$ ou $60 \mathrm{~g}$ etc. Estes números servem para avaliações individuais mas, como avaliação para ser utilizada por um número grande de pessoas, deixam a desejar.

Uma aproximação pode ser dada com o cálculo do volume do lobo, com a ressalva de que a profundidade será difícil de ser avaliada adequadamente. A fórmula utilizada para o cálculo do volume dos lobos é: (Volume $=$ comprimento $\mathrm{x}$ largura $\mathrm{x}$ profundidade $\mathrm{x} \pi / 6$ ). A medida mais acurada poderá ser obtida pela ultrasonografia, tanto dos lobos como dos nódulos, entretanto em se tratando de bócios mergulhantes, a presença do esterno impede que o cálculo do volume da glândula seja realizado por este método e então, a tomografia computadorizada ou a ressonância nuclear magnética deverá ser solicitada para esta finalidade.

\section{Sinal de Pemberton}

O bócio multinodular pode causar obstrução da traquéia e quando retroesternal também a obstrução da veia cava superior. O sinal de Pemberton (Figura 5) aparece quando se eleva o braço do paciente acima da cabeça. Esta manobra faz com que o paciente fique dispneico, com distensão das veias do pescoço, pletora facial ou com estridor ${ }^{7}$.

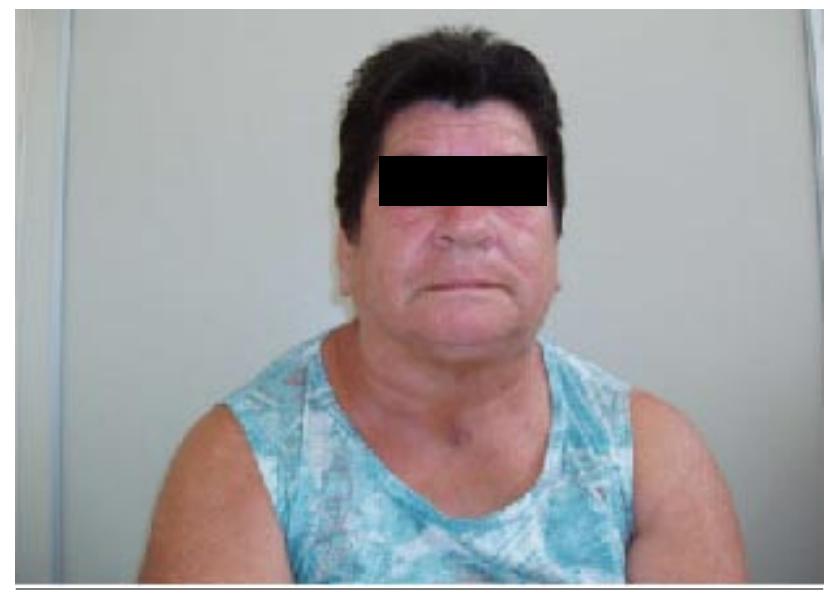

A) Paciente na posição inicial

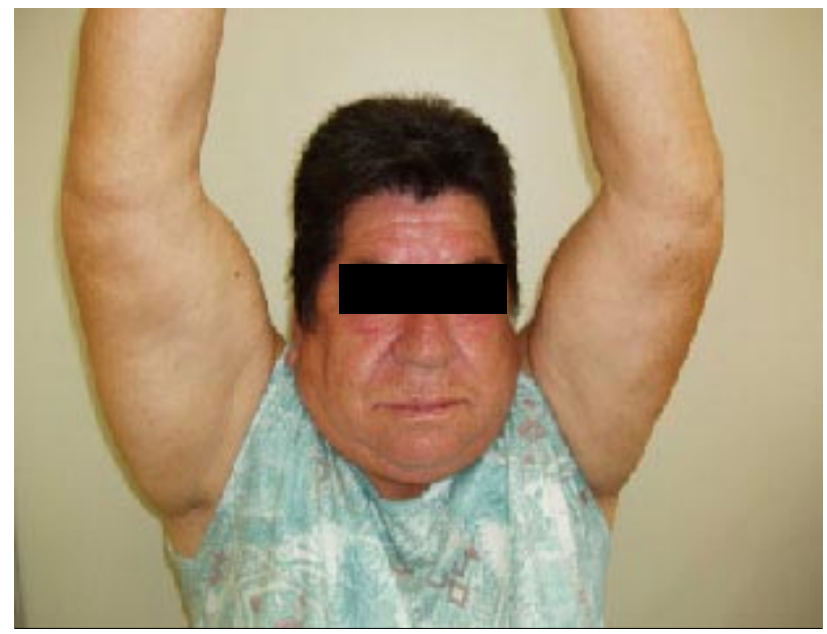

B. Paciente com os braços elevados. Notar a pletora facial.

Figura 5. Sinal de Pemberton

Maciel LMZ. Thyroid Exam. Medicina (Ribeirão Preto) 2007; 40 (1): 72-77.

ABSTRACT: Although the physical examination of the thyroid is not considered a simple procedure for a great majority of physicians, it should be part of the systematic clinical evaluation of a patient, considering that usually the palpation of the gland is the only technique for detecting diseases of the thyroid. Examination of this gland should include inspection, palpation and auscultation. The normal thyroid gland, generally, is not visible. For an adequate palpation of thyroid, it is essential a correct anatomical localization of the gland. Size, consistency and mobility of the lobes, presence or not of pain or changes on surface of gland must be described. The size of the thyroid gland should be classified as normal or increased (goiter). Goiter can be diffuse or nodular (uninodular or multinodular goiter). Thyroid auscultation should be performed only in patients who present symptoms and/or signals of hyperthyroidism.

Keywords: Physical Examination. Thyroid Gland. 


\section{REFERÊNCIAS}

1 - Simon HB, Daniels GH. Hormonal hyperthermia: endocrinologic causes of fever. Am J Med 1979; 66: 257-63.

2 - Hegedus L. Clinical practice. The thyroid nodule. N Engl J Med 2004;351: 1764-71.

3 - Dayan CM, Daniels GH. Chronic autoimmune thyroiditis. N Engl J Med 1996;335: 99-107.

4 - Gwinup G, Morton ME. The high lying thyroid: a cause of pseudogoiter. J Clin Endocrinol Metab 1975;40: 37-42.

5 - Melnick JC, Stemkowski PE. Thyroid hemiagenesis (hockey stick sign): a review of the world literature and a report of four cases. J Clin Endocrinol Metab 1981;52: 247-51.
6 - Bürgi U, Peter HJ, Gerber H. Clinical manifestation and management of nontoxic diffuse and nodular goiter. In: Braverman LE, Utiger RD, eds. Werner and Ingbar's the thyroid : a fundamental and clinical text. 7th ed. New York: Lippincott - Raven Publishers;1996. p. 896-901.

7 - Blum M, Biller BJ, Bergman DA. The thyroid cork. Obstruction of the thoracic inlet due to retroclavicular goiter. JAMA 1974;227: 189-91.

Recebido em 17/10/2006

Aprovado 27/11/2006 